\title{
History, Quantification, and the Social Sciences
}

\author{
JEROME M. CLUBB \\ University of Michigan \\ ALLAN G. BOGUE \\ University of Wisconsin
}

During the past 20 or more years change and ferment has invigorated the study of the past. New approaches to historical inquiry have been advocated and pursued, historians have developed new interest in formerly neglected areas, and practitioners of other disciplines have begun to show renewed interest in using a historical dimension in their research. The contributors to this special issue reflect on these and related developments. Their reflections, however, incorporate several disciplinary perspectives and are cast in terms of the participants' own research and intellectual orientations. This essay is not an introduction to this issue. Rather we have taken it as an opportunity to consider recent developments from our own perspective and to state our own views and conclusions, even though they are incomplete and, perhaps also, deviant from the views of others, including some of the contributors, who have been no less involved in the agitations, explorations, and achievements of the last two decades. We are concerned here with the

AMERICAN BEHAVIORAL SCIENTIST, Vol. 21 No. 2, November December 1977

(C) 1977 Sage Publications, Inc. 
emergence of social-scientific approaches to historical inquiry. More specifically, we are interested in assessing the degree to which recent developments in the historical discipline and in the related social sciences look toward a mode of historical inquiry which promises to contribute to scientific knowledge of human behavior.

Social scientists of the 1940s and 1950s tended to neglect the past as a locus of scientific inquiry. And by social scientists we mean scholars of any disciplinary orientation who try to identify regularities and uniformities in human affairs through the use of empirical methods and who seek to develop theoretical formulations that link together and explain those regularities. Obviously, social scientists so defined have not completely ignored historical inquiry. Economists have long shown a pronounced, but by no means dominant, interest in the scientific investigation of historical trends and patterns and other long standing examples of scientifically oriented historical inquiry are to be found in such social-science disciplines as demography.

Yet, it is also clear that the scholars who contributed to the emergence of self-conscious and aggressive dedication to the development of a science of human behavior in psychology, sociology, and political science focused primarily on contemporary events and subjects. Indeed, rejection of historical inquiry, of the historical method, and of historical, or genetic, explanations of human behavior, was a major element in the behavioral revolution in these disciplines. The behavioralists emphasized methods of data collection - personal interviews, questionnaires, sample surveys, laboratory experiments, and other methods of direct observation - that could not be employed in the study of the historical past. Such methods of data collection came to be identified with scientific modes of inquiry and since they could not be applied to the study of history, many behavioralists concluded that it was impossible to study history scientifically.

This is not to say, of course, that systematic investigation of the past was neglected by historians. System, rigor, and discipline are hallmarks of historical inquiry. But the traditional approaches of historians were not oriented toward identification and study of empirical regularities nor toward the development of theoretical formulations. Indeed, professional historians tended to deny the existence-or, at least, the importance-of regularities in human behavior and to assume an explicitly atheoretical posture. Most historians rejected, often with derision, the possibility and desirability of a science of human behavior.

Major signs of change have become apparent in all of these respects. Social scientists have developed a new, although by no means domi- 
nant, interest in historical phenomena. We do not intend to explore the reasons for this reorientation. Obviously, however, it reflects interest in understanding long-term processes that cannot be examined in the context of a single, limited temporal era. We can also surmise that this change in focus reflects concern for the generality of findings and conceptual and theoretical formulations based on essentially crosssectional investigations of a single time period. Thus, increasing numbers of researchers apparently have recognized that examination and comparison of the events and processes of even temporally remote eras can provide a means to refine, test, and generalize conceptual and theoretical formulations. And we can also suspect that greater awareness of the frailties of even such powerful methods of data collection as the sample survey has developed.

But we are more concerned here with developments within the historical discipline. From our point of view, the most striking development of the 1960s and 1970s was the growth and advocacy of a variety of new histories. It is difficult to trace the development of these new scholarly preoccupations of historians, and indeed some innovations were less new than their advocates suggested.

It is also difficult, or impossible, to identify common denominators, although several dominant themes in the new histories do stand out. One such tendency was the injunction to study the politics, society, and economy of the past from the perspective of the grassroots - to examine the history of ordinary people, of minorities, blacks, women, and other formerly neglected groups. The past, in other words, was to be studied from "the bottom up." Such admonitions and efforts illustrated, in the view of some, an egalitarian or leftist bias that paralleled movements of the time. But whatever is to be said of ideological roots, the new emphasis marked a welcome departure from the elitist orientation of more traditional history. And there were other implications as well. Not the least of these, in our view, was the impetus that these new preoccupations provided to the use of formerly neglected categories of source material and to the application of new methods and conceptualizations.

A second and related characteristic of the new histories was their affinity with the related social sciences. That affinity was illustrated particularly well in the new economic history, or "cliometrics," where the debt to contemporary economic theory and method was both heavy and explicit. The relations between the new histories and the social sciences were most clear in the area of method. Here quantification became the rallying cry. Research at the grassroots or among the rank 
and file involved the use of source materials-census records, biographical sketches, wills, city directories, election returns, and the like - that are massive in volume but low in the amount of information to be extracted from any individual item. To arrange, organize, manipulate, and comprehend massive arrays of data extracted from such sources required the use of statistical, electronic, and mechanical tools, and the value of such devices was emphasized by the successes which the related social sciences had already achieved through their use.

It would, of course, be erroneous to suggest that the historians of the 1950s and 1960s were the first members of their discipline to use quantitative methods and source materials. As Robert W. Fogel (1975) has pointed out, historians have always quantified both explicitly and implicitly, and students of other and more quantitatively oriented disciplines have always studied the past. Various historians, perhaps in search of legitimacy, have identified the beginnings of modern, quantitative historical research in the writings of A. Lawrence Lowell, Orin Libby, Charles Beard or Frederick Jackson Turner, among American historians; with the Annales school in France; or with Buckle and Namier on the British side and other beginning points of equal plausibility could be suggested. Although interesting, the origins of movements are less important than their substantive manifestations and results.

\section{THE NEW QUANTITATIVE HISTORY}

Since approximately the mid 1950s a growing minority of professional historians have self-consciously employed quantification in their research and advocated its use in their writings and teaching, sometimes with a certain revolutionary fervor. Moreover, many historians - both quantifiers and their critics - as well as observers outside the discipline, have seen the use of quantitative methods and materials as the primary point of intersection between the historical discipline and the related social sciences. Many have interpreted the growing use of quantification among historians as evidence that the history discipline was moving toward a legitimate place among the social sciences. That we believe to be a rather naive view of the situation.

Technical skill and expertise in the use of quantitative methods and materials have varied widely among the new historians. However, it is clear that in these terms the new economic historians have been in a 
class by themselves. Blessed by relatively rich lodes of relevant data and trained and working in the tradition of a social science whose members have long employed quantitative approaches within relatively sophisticated theoretical frameworks, the cliometricians enjoyed a considerable advantage over other historians. Among quantitative historians concerned with political, social, urban, and demographic history, technical expertise in statistics and related areas has been unevenly distributed. In the quantitative publications of these historians, tables of raw numbers, unbenefited by any form of standardization, now vie with complex equations. During the past 20 years, however, the modal level of technical expertise among this group has steadily increased. A growing minority of younger historians have received formal training in statistics and are joining an older and largely self-trained generation, and indeed, a few historians are now venturing in the direction of methodological innovation.

This is certainly not to say that an orgy of self-congratulation is in order. The level of technical competence in statistics and related areas is still abysmally low among historians compared to that of the related social sciences. Courses in quantitative methods for historians, variously labeled, have appeared in history departments throughout the nation, although many such courses disseminate more misinformation than sound training. Even so, conditions have improved. Much of the early mystified awe with which the computer was held has now dissipated, although a few still see it as a substitute for cerebration; some of the worst statistical blunders have disappeared from the literature; the untutored historian at least runs the risk of informed criticism; and a literature marked by considerable technical sophistication and complexity is now appearing.

The modest improvement of technical sophistication has been greeted with mixed reactions. Neanderthal traditionalists, including some who are ostensibly friendly critics, insist that jargon and an excessive reliance on numbers is destroying the literary quality that, they maintain with considerable exaggeration, has been a fundamental characteristic of historical writing. Quantification, in their view, dehumanizes history and substitutes tables of numbers for humane understanding of the personalities of the past. Less paranoiac scholars recognize that quantitative methods and materials have already contributed to deeper and more precise knowledge and have allowed investigation of the conditions and behavior of ordinary men and women of the past who were usually neglected by traditional historians. Thus, 
quantitative approaches have added a humane dimension to history that traditional approaches with their exclusive dependence on elite sources could not provide. These same historians, however, also express concerned recognition that growing technical proficiency is leading to a form of history that cannot be read effectively, much less critically evaluated, by the technically untrained.

In some ways more surprisingly, the growing technical expertise of quantitative historians has not enthused some of the founders of the new history. These scholars have deplored what they see as an excessive emphasis on quantitative methods. They have suggested, in effect, that quantitative methods have become unnecessarily technical, that too much concern has been directed to complicated varieties of mathematical analysis, and they have called for greater concern for theory. In their more extreme form, these views seem to denigrate any concern for matters of technique and to woefully neglect both the complexities of quantitative methods and the hazards involved in their misapplication. It is certainly true that historians have paid too little attention to theory and it is equally the case, in our view, that elegant methods are of little value without conceptual and theoretical formulations. On the other hand, theories are also of little value without appropriate methods to test and refine them. In these latter terms, the technical expertise of historians is not only far too low for comfort but too low to justify the view that concern for method has been excessive.

Indeed, it seems clear that while historians have recognized the value of quantitative techniques, and have shown signs of increasing proficiency in their use, they have not yet directed sufficient attention to broader issues of methodology. In the main, the new quantitative historians have been concerned with techniques of data analysis. Substantially less attention has been devoted to matters of conceptualization, design, and measurement. As in the case of the other social sciences, the problems that concern historians involve essentially nonempirical concepts such as cause, force, and attitude. The conduct of research requires that these concepts be translated into empirical measures and indicators. In general, far too little attention has been directed to these processes of operationalization and measurement. Thus, popular behavior or the recorded votes of members of legislatures are treated as direct measures of attitudes; occupation or income are taken as direct measures of social status; and causal 
relations are asserted without an appropriate test or analytical warrant. Neglect of the "measurement gap" is, of course, particularly hazardous in view of the paucity and inadequacy of historical-data sources.

Problems of conceptualization also occur in the tendency to select inappropriate statistical models for data reduction and analysis. All too frequently, statistical models are correctly applied in technical terms but are inappropriate to the research problem or the historical process of concern. Selection of appropriate analytical models requires that problems and processes of concern be carefully conceptualized. Otherwise, inappropriate statistical applications result.

The point can be made more generally. Despite the heavy emphasis that the new historians placed on quantification, they were much less quick to recognize the central importance of conceptual equipment in their work. Contrary to a long-standing historiographical dictum, data do not "speak for themselves." Before the data can speak, conceptualization is necessary. Conceptual models, frameworks, and theoretical formulations are a necessary basis for assigning meaning to observed statistical relationships and patterns and are required to suggest relationships that ought to be present in relevant data if other propositions are to be accepted. Despite the warnings of Potter (1963), the new historians did not realize consistently that the necessity of conceptual formulations-of generalizations-does not go away merely because it is unrecognized. As a consequence, generalizations and theoretical formulations, often drawn from the social sciences absorbed in the sophomore year or from common sense, became the implicit and, hence, untested covering laws that provided the real structure of explanation in countless quantitative historical works.

The results of these failures were several. Scholars published excessively empirical works in which quantitative data were marshalled in impressive displays but the conceptual apparatus that gave them meaning and that provided a reason for their display was simply assumed. Investigators assigned substantive significance to particular statistical relationships, but other possible associations went untested or an equally strong relation was dismissed because of some implicit, and untested, assumption or generalization. At another level, historians have witnessed the collapse of superficially plausible and impressive explanations of historical phenomena as implicit, explanatory generalizations were revealed to be inadequate on prima facie grounds or failed empirical test, as empirical indicators of underlying concepts 
were shown to be inadequate, or as analytical models were demonstrated to be inappropriate.

It is certainly correct that the new quantitative historians have given too little attention to theory. Yet their technical and, particularly, their methodological and conceptual apparatus also remains inadequate to their needs. In reality, the appropriate formula for the future appears to require simultaneous emphasis on technique, method, and conceptualization as well as on the use and development of theory.

\section{HISTORY AND THE SOCIAL SCIENCES}

As we have noted above, quantification has been seen by some as a primary point of intersection between history and the social sciences, and growing use of quantitative methods and materials by historians has been taken as an indication that history is becoming a full fledged social science. Nowhere was the tendency to confuse quantification with social science more poignantly illustrated than in the remarkable odyssey of many historians in search of financial support for research. That wandering took them, figuratively, print-out in hand, to the new National Endowment for the Humanities. There they were told that, because quantitative in character, their work did not fall within the legislative mandate of the Endowment and were diverted to the National Science Foundation. There they found their work was equally unwelcome. Confusion was compounded when they learned that colleagues in other social science disciplines had received grants for research that clearly involved historical investigation. They concluded that they had been discriminated against because of their discipline but, in simple terms, their proposed research was not scientific nor calculated to contribute directly to scientific knowledge.

In the early days of the new histories, the use of quantitative methods and materials was, as Thomas J. Pressly once put it, a form of historical fundamentalism. The use of these methods and materials reflected the historian's professional obligation to use all relevant sources, to employ all useful methods, and to cast sources in new ways in order to marshall the best and most complete evidence and thereby gain an improved understanding of the past. The goal was to bring fresh evidence to bear on questions of long standing interest to 
historians - did the common man really participate fully in the politics of the Jacksonian period, for instance, and this goal continues to underlie much, if not most, of the work of the new quantitative historians.

No objections can be raised to this form of history. The effort to describe, explain, and reconstruct the past as an end in itself is legitimate and laudable and in keeping with the traditional goals of historical inquiry. The use of quantitative methods and materials in the service of that end is also in keeping with basic, and traditional canons of historical inquiry and has obviously contributed in major ways to new knowledge of the past. But two additional points need to be made. In the first place, the goal of describing and explaining the past as an end in itself in no way lessens the need for improved technique and method nor does it mitigate the need for greater attention to theory. Secondly, this goal is neither completely congruent with, nor does it fully subsume, the goals of social science. To put the matter differently, the use of quantitative methods and materials to describe, explain, and reconstruct particular historical events and periods does not make history a social science.

Readers of this volume will note that the authors of many of the works discussed are not historians by discipline, illustrating the growing trend in various social science disciplines to turn once more to the laboratory of the past for evidence. As yet, however, the work of such scholars differs rather markedly from that of quantitative historians. The social scientists specify their theoretical concerns, while historians are much more apt to begin with an introductory preamble that describes the importance of the specific historical problem or the specific historical question addressed in their work. But the differences also involve the historian's predeliction for the narrative form.

The narrative form of the historian involves not merely stylistic format, primarily descriptive prose, but also the form of organization that underlies such narrative. The basic organizing tactic of historians is to describe the unfolding of events in chronological sequence and there are sharp limits to the degree to which historians will play games with the concept of time.

The work of the new quantitative historians, like that of other historians, has tended to involve, as a central element, meticulous effort to reconstruct past events, to describe what actually happened in particular historical circumstances and to explain those happenings, 
usually in terms of individual motives and attitudes. In doing so, careful regard is paid to chronological order and to specific context, and the resulting description of past events is seen as an end in itself.

Historically oriented social scientists, on the other hand, are more cavalier where temporal order and specific context are concerned. Reconstruction of past events is not an end in itself; rather the past is used as a source of data and evidence. Events, persons, and institutions of the past and the present are classified and compared to develop, test, and refine general statements about human behavior with much less emphasis on the context of calendar time. This is by no means to say that all social scientists, whether historically oriented or otherwise, successfully or even consistently pursue these goals. It is to argue, however, that identification of regularities and development of theoretical formulations are central goals of social scientific inquiry.

Viewed in these terms, and as others have pointed out, the new quantitative historians, as other historians, must be seen as primarily consumers rather than producers of generalizations and theoretical formulations. As we have suggested above, the new findings which quantitative historians have contributed do not rest exclusively on rigorous analysis of hitherto neglected historical data. They rest as well on generalizations and theoretical formulations borrowed from the related social sciences or drawn from native common sense. Many cliometric studies, particularly, illustrate the use of contemporary economic theory to fit together and make sense of historical data. It has been argued that in this process cliometricians torture both economic theory and the historical data, but our point is only that such studies use contemporary economic theory to reconstruct and explain the past.

In their efforts to answer long-contested questions in American economic history, the cliometricians have only done in an explicit, highly skillful, and rigorous way what historians have always done. Historians frequently borrow-often implicitly, without explicit acknowledgment, and perhaps without fully conscious recognitionconcepts and theoretical formulations from the related social sciences. These concepts and formulations are then used to select, link together, interpret, and make sense of the facts and events of historical situations. In this way, it is possible to construct plausible, meaningful, and intuitively reasonable descriptions of those situations. Although when implicit, this borrowing process is objectionable from the standpoint of verification and in terms of the need to distinguish between empirical 
fact, on the one hand, and concept and theory, on the other, the process itself is not. Without it, credible historical accounts probably could not be constructed. On the other hand, a history that only borrows concepts and theoretical formulations from the related social sciences, and which is neither intended nor designed to test and refine those theories or to contribute to the development of theoretical formulations, can be described at best as applied social science.

Viewed in the broadest terms, then, the past 20 or more years have witnessed progress toward a more comprehensive history-a history that takes as its purview a wider range of the varieties of past human experience and behavior, that is concerned with formerly neglected human institutions and processes, and which is not limited in its scope to the few of power and position but which is concerned as well, and perhaps primarily, with the conditions, experiences, and behavior of the ordinary people of the past. It is a history that has grown in part out of the traditional imperatives of the craft and which, in obedience to those imperatives, seeks to use all relevant sources and all useful materials. Thus, the recent past has witnessed increasing use by historians of hitherto neglected sources and increased employment of the methods and tools of quantification, and in the use of those methods and tools the new historians have become steadily more rigorous and more expert. The new historians have drawn on the related social sciences not only for tools and methods but also for concepts and theory which they have applied with increasing effectiveness to better describe, explain, and understand the events and processes of the past. While this borrowing process has too often been implicit, and generalizations and theories have too often been unconsciously and naively accepted, it is also possible to detect the development of a better informed, more self-conscious, and more systematic effort to apply the findings of the social sciences to the task of reconstructing and understanding the human past. This is not to say that the new history has arrived. The new historians need to pay still greater attention to technique and method and, perhaps above all, to theory and to the conceptual and epistemological foundations of their work. But clearly progress has been made.

And these may be aspirations enough. A more complete, more comprehensive, more replicable view of the past that is at least consistent with the theories and generalizations of the contemporary social sciences would not be a trivial accomplishment. The new histories 
appear to be moving toward such a view, however halting their progress sometimes seems. Yet the new histories remain primarily consumers of generalizations and theories rather than producers. It remains to be asked whether the study of the past can contribute to general and scientific knowledge of human behavior?

\section{HISTORY AS SOCIAL SCIENCE}

We cannot review in detail the long and often tiresome debates over whether history is or should be a science. Nor will we rehearse either the sometimes quaint views of philosophers as to the nature of the historical enterprise or the often naive and self-serving efforts of historians to prescribe and dictate the boundaries of the historical discipline. Rather, we will ask here only: can the study of the past serve as a means to test, refine, and develop scientific theories of human behavior?

From one perspective the answer to such questions is surely yes. Countless generalizers and theorists have used, often to their peril, the descriptions of past events provided by historians as grist for their theoretical mills. But the implications of the questions are broader. We must consider briefly the obstacles in the way of historical inquiry directed to the development of scientific knowledge and ponder its limitations.

Some of the obstacles in the way of such an enterprise seem amenable to relatively straightforward solution-better training in statistics and mathematics and in the tools of quantitative inquiry, greater and more rigorous familiarity with the conceptualizations and theoretical formulations of the related social sciences, and sensitive attunement to problems of measurement and conceptualization. But reservations have been raised on other grounds by individuals with impressive credentials within the new history. One set of perhaps fundamental reservations concerns intrinsic characteristics of the data available for the study of the past. Some varieties of quantitative or quantifiable data exist in embarrassingly massive amount, but more frequently the available data are frustratingly fragmentary. For many aspects of past human activity and for vast areas of the historical terrain, virtually no data exist whether quantitative, quantifiable, or otherwise. 
Murray Murphey (1973) identifies eight types of data relating to past populations of which only one category includes data equivalent in completeness to that which social scientists concerned with contemporary phenomena can obtain. And, of the historical data available to American historians, only the manuscript rolls of the federal census fall into that category as Murphey views the matter.

Murphey lists five methodological problems which are confronted in using historical data to "confirm law-like statements"-the problems of quantity, aggregation, sampling, informant bias, and measurement. Quantity, aggregation, and informant bias are all characteristics of sources that call for the development of techniques allowing the evidence to be used for particular purposes with maximum facility or confidence. Sampling, on the other hand, not only may be a device for solving the problems posed by large quantities of data, but may, if theories are developed appropriately, provide models or guidance which allow more confident use of incomplete data. Although these four issues are serious when viewed in their theoretical aspects, they are less formidable than the general problem of measurement. Given the categorization of data, described by Murphey, can accurate indices of societal change be constructed? After a sophisticated review of the current methods of historians, Murphey pessimistically concludes (1973: 201) that present methods "for confirming general hypotheses regarding past populations cannot meet the standards which now prevail in the social sciences."

The difficulties discussed tellingly by Murphey could be stated in a variety of ways but they are major problems which cannot be ignored. It is also possible, however, to argue that they may not be as fundamental as he sometimes seems to suggest. The view of the efficacy and reliability of the data collection and measurement techniques of the contemporary social sciences on which his critique of historical sources rests seems excessively exalted. Social scientists - and, for that matter, physical scientists in such fields as astronomy and geology-have confronted similar problems and have developed at least limited strategies for their solution. It is certainly the case, however, that solutions to the problems Murphey identifies would require effort in new directions, and not only methodological research but also, for example, research into such areas as the sources and nature of bias in historical data and into the purposes and nature of historical information collec- 
tion, recording, and retention procedures. Above all, solutions would require substantially more rigorous and more extensive methodological training than historians now receive. And it may be that these problems impose sharp limitations on the nature and extent of knowledge that may be gained by empirical historical inquiry.

But if we assume for the moment that such difficulties are amenable in principle to at least partial solution, and the assumption is a large one. we can ask what the characteristics of historical inquiry devoted to development of general theories of human behavior might be. It seems clear that the focus of historical inquiry would shift in major ways. Meticulous reconstruction of past events and historical situations would be geared to theoretical concerns. Topics and directions of research would be dictated by explicit theoretical formulations. Substantial attention might be directed to classification of historical events, individuals, institutions, and populations in terms of characteristics relevant to particular conceptual or theoretical formulations. Classic historical problems and questions that have long preoccupied historians would receive less attention; research topics would be selected, instead, in terms of tensions within theoretical formulations or as promising targets of opportunity to test and refine elements of those formulations. And, it is likely that descriptions of past events would be valued less as ends in themselves but would be seen instead as means to more general, and more timeless, theoretical knowledge of human affairs.

It is probable as well that such a history would be more modest in its aspirations and pretensions than traditional history has been. Historians of this persuasion might consider reconstruction of the specific motives and feelings of long-dead individuals, however interesting, as beyond the reach of empirical inquiry and better left to the imaginative, intuitive, and evocative methods of poets, novelists, and impressionistic historians. Such historians might not venture into "moral and aesthetic realms," seek "to comprehend the totality of human behavior," or attempt to grasp history as a "seamless web" (Fogel, 1975). They might be satisfied with a more constrained and contingent form of knowledge that was sharply limited by scientific canons of verification.

A genuinely social-scientific history probably would be substantially different from even the new history that is now emerging. It would be 
limited by characteristics of historical sources such as those described by Murphey. Such a history would be more abstract and lack the rich and evocative sense of time and place that characterizes traditional historical narratives. Indeed, time and place might become little more than variables that index change and cultural or national differences. The goal of understanding and describing the past might recede to be replaced by a more timeless, but nontheless provisional, theoretical view of human behavior.

\section{PROBLEMS AND PROGRESS}

To assume that any significant number of historians are likely to pursue a form of social-scientific history that even remotely resembles that outlined above may be only to indulge in the wildest of flights of fancy. The fact that a few historians and a large number of historically oriented social scientists have advocated or already taken essentially similar directions may only suggest the reaction of most historians: it would not be history. But even if we consider the present state of the new history and project an even modest increase in technical, methodological and theoretical sophistication, which will surely occur, we can recognize the likelihood of growing difficulties of communication, training and orientation within the profession. If to this projection is added development of interest in a genuinely social-scientific history, these difficulties would obviously be aggravated.

Historians specialize in widely diverse temporal periods, historical themes and problems, and geographic, cultural or national areas. But aside from relatively rare subfields that involve esoteric languages or ancillary skills, communication among historians even across boundaries of specialization usually has not been a serious problem. Historians traditionally have attempted to avoid-without complete success, it should be noted-specialized terminology and have sought to communicate in the language of the literate layperson. Thus it has been possible for historians to read effectively studies outside their fields of specialization and transmit findings to their students in classroom situations or even employ those findings in their own work. Since traditional historical methods are relatively straightforward and, with a few exceptions, do not vary from one subfield to the other, it is 
possible, at least to some degree, for historians in one area of specialization to critically evaluate work in other areas.

The new history seriously challenges this happy situation. For 20 or more years, some historians have been publishing research which the vast majority of their colleagues and history undergraduate and graduate students cannot read and critically evaluate because of its methodological and conceptual complexity. It is true that much of this work has been of transitory importance. Such work, however, is steadily growing in volume, it is of increasing technical, methodological, and theoretical complexity, and the findings are of mounting importance. While sound scholarship and instruction dictate that it be read and critically evaluated, the majority of historians are increasingly ill-equipped to do so.

The research of the cliometricians is at present the most striking example of the problem. The mathematical complexity of that work transcends the training of most historians including many of the new historians in other fields. The difficulty is not, however, simply a matter of mathematics. Cliometric history is also grounded in contemporary economic theory. Critical estimation and measurement procedures, behavioral models, and basic assumptions which underlie the work of the cliometricians are drawn from that body of theory. Thus, their work of this type cannot be fully comprehended and its limitations and contingent nature recognized, nor can it be critically evaluated without some comprehension of economic theory. 1

And the work of the cliometricians must probably be seen as a sign of the times. As the new historians of politics and society come to draw on the increasingly elaborate and complex conceptual and theoretical formulations of the related social sciences, similar problems of comprehension and evaluation will undoubtedly develop within these subfields of history. We can add to this situation the work of historically oriented political scientists and sociologists which is frequently more technically and conceptually complex than that of the new historians. When the increasingly mathematical nature of the related social sciences is also noted, it becomes obvious that historians face a major communications gap both within their own discipline and in relation to other fields of inquiry.

The reactions of historians have varied. A few have attempted to implement the Barzunian tyranny and have simply ruled, ex cathedra, all such work, whether by other historians or social scientists, as out 
of bounds and not history. Others have simply ignored the whole thing apparently in the hope or belief that it will all go away. More commonly, however, interested historians have merely accepted or rejected the results of technically and theoretically complex investigations without critical evaluation. In some cases, historians have merely relied on the criticisms of alleged experts. But, supposed experts have often not been particularly expert and their criticisms have sometimes been dictated by a bias against all quantitative or theoretical work. Many of the criticisms among the more advanced practitioners also involve what amounts to fine tuning, which, although important and of keen interest to the initiated, is sometimes couched in extreme or polemical language that obscures the fundamental contribution of the work under review. Unfortunately, unsophisticated historians have sometimes taken such specialized criticisms as grounds for rejecting important contributions.

A few historians have attempted to develop sufficient expertise in technical and theoretical areas to allow them to absorb the findings of new historians and social scientists into their classroom instruction. But retraining programs are few and obstacles to participation in them are many. To date, the National Endowment for the Humanities (the official guardian of history) has given little recognition to the need of even traditionally oriented historians to gain conversance with technical skills if they are to pursue their craft effectively. Thus, in substantial numbers, interested and concerned historians who are motivated by the traditional canons of their discipline are simply denied the requisite tools to understand a growing body of literature that is relevant both to their teaching and research.

Nor are the signs for the future particularly reassuring. Little has been accomplished in providing training in quantitative analytical skills for undergraduate majors in history. Some instructors in a few widely scattered institutions have experimented with incorporating quantitative laboratory-type projects into basic courses. As yet, however, they have developed little in the way of effective teaching materials for history that are comparable to those employed in the related social sciences. Few, if any, history departments require or even strongly recommend that their undergraduates acquire training in elementary statistics.

The issue of obligatory statistics courses for undergraduate majors in history is broader than this discussion suggests. Historians have 
long depended in an informal way on the related disciplines to provide assistance in defining problems of interest. And much of this process has gone on at the undergraduate level before history majors have moved to the heavy specialization in history typical of graduate school programs in this discipline. The failure to require statistics in the undergraduate history curriculum means that large sectors of social science offerings are now either closed to history majors or so intimidating that they avoid them. Many history majors therefore choose their electives solely in the areas of soft social science or in the humanities and obtain an education that is unfortunately old fashioned and incomplete.

The picture is different where the declining population of graduate students in history is concerned. At this level of instruction, the number of new historians and the weight of their publications has worked to bring about some change in the curriculum. In many departments, courses in quantitative methods for historians are being offered. Frequently, however, such courses are offered by historians who are only partially trained themselves or these courses are given over to essentially remedial training. Graduate students are sometimes urged to acquire advanced training in statistics and related areas in other departments, but lack of prerequisites and the weight of other requirements frequently militate against this course. Thus it is still possible, and even probable, that the neophyte historian will pass through both undergraduate and graduate work in entire innocence of quantitative training.

A new and more technically and conceptually complex form of history has emerged and there are even signs of interest in a genuinely social-scientific history. Yet historians and the historical discipline have been slow to acclimate to these developments. Indications of major cracks within the discipline have appeared as a consequence. Many of the new historians have found greater communalities of interest among colleagues in social-science disciplines than in their own discipline. The situation has been aggravated by history editors and reviewers who insist that the technical and theoretical apparatus, and the results of supporting data analysis, be consigned to footnotes and appendices, or even separate volumes, as a condition for publication. Since these elements are intrinsic to their arguments and findings, new historians have often turned to social-science publications and to specialized journals and collections for which, in any event, the audience is likely to be more receptive and congenial. There is also some 
indication that quantitative and social-scientific approaches to history are developing within, or migrating to, social science departments and disciplines, as in economic history and, to a lesser extent, in the case of demography as well. Whether the process will also occur in other areas remains to be seen.

The social-scientific disciplines-and, for that matter, some of the humanistic disciplines-grew out of history. The result of that secession, from some perspectives, was to leave the historical discipline as only a residual congeries of the temporal dimensions of the seceding disciplines. A further secession would look toward even greater truncation of the historical discipline, or even its demise.

\section{NOTE}

1. These problems are suggested by Peter D. McClelland (1973).

\section{REFERENCES}

FOGEL, R. W. (1975) "The limits of quantitative methods in history." Amer. Historical Rev. 80 (April): 329-350.

- - and S. L. ENGERMAN (1974) Time on the Cross. Boston: Little Brown.

McCLELLAND, P. D. (1973) "Model-building in the new economic history." Amer. Behavioral Scientist 16 (May/June): 631-652.

MURPHEY, M. G. [ed.] (1973) Our Knowledge of the Historical Past. Indianapolis: Bobbs-Merrill.

POTTER, D. M. (1963) "Explicit data and implicit assumptions in historical study," pp. 178-194 in L. Gottschalk (ed.) Generalization in the Writing of History. Chicago: Univ. of Chicago Press. 